\title{
Quais danos os raios podem causar em nossa vida? Uma sequência didática investigativa
}

\author{
Juliana Gonçalves Leite \\ Instituto Federal de Educação, Ciência e Tecnologia Fluminense (IFF) \\ (juliana_gleite@hotmail.com) \\ Cassiana Hygino Machado \\ Instituto Federal de Educação, Ciência e Tecnologia Fluminense (IFF) \\ (cassianabarretohygino@gmail.com) \\ Renata Lacerda Caldas \\ Instituto Federal de Educação, Ciência e Tecnologia Fluminense (IFF) \\ (renata.caldas@iff.edu.br) \\ Simone Dias Pinto Costa \\ Instituto Federal de Educação, Ciência e Tecnologia Fluminense (IFF) \\ (simonediaspinto@bol.com.br) \\ Suzana Maria Santos de Oliveira Alencar \\ Instituto Federal de Educação, Ciência e Tecnologia Fluminense (IFF)
}

(suzi1alencar@gmail.com)

Resumo: Este trabalho teve como objetivo investigar quais implicações para a aprendizagem sobre eletrostática, na temática sobre raios, podem ser obtidas com o uso do método estudo de caso, na forma de sequência didática em três passos: 1) leitura e discussão de um caso baseado em fatos reais, sobre tempestades e raios; 2) exposição oral sobre eletrização, corrente elétrica e diferença de potencial na formação dos raios, com avaliação, por meio de um jogo via aplicativo Plickers; 3 ) retomada à problemática do caso, para solução final proposta pelos alunos. As respostas iniciais e finais foram analisadas com vistas à evolução do conhecimento. A análise das respostas evidenciou que todos os grupos responderam com base no conhecimento empírico. Na retomada do caso, após abordagem dos conceitos físicos, os alunos mudaram a concepção a respeito do caso e passaram a analisá-lo cientificamente. Dessa forma, foi possível verificar que a sequência didática embasada no método de estudo de caso contribuiu para a aprendizagem de conceitos científicos, colaborando para uma aprendizagem mais significativa dos conceitos de eletroestática, de uma forma mais dinâmica em sala de aula. Acredita-se que a eficácia e o sucesso do método possam colaborar para tornar as aulas de física mais motivadas e atraentes.

Palavras-chave: Ensino de Física; Raios; Eletricidade.

\section{What damage can lightning cause in our lives? An investigative teaching sequence}

Abstract: The purpose of this study is to investigate which implications for electrostatics' apprenticeship on the Lightning theme can be obtained using the Case Study method by in the form of a didactic sequence: 1) Reading and discussing of a case based on real facts of thunderstorms and lightning; 2) oral exposition about electrification, electric current and potential difference on the lightning's formation, measuring into a game using the Plickers app; 3) returning to the problem of the case for the final solution proposed by the students. The initial and final responses have been analyzed with a view to the evolution of knowledge.

The response analysis showed that all groups responded based on empirical knowledge. At the resumption of the case, after approaching the physical concepts, the students changed the case's conception and began to analyze it scientifically. Thus, it was possible to verify that the didactic sequence based on the Case Study method contributed to the learning of scientific concepts, contributing to a more meaningful learning of electrostatic concepts, in a more dynamic way in the classroom. It is believed that the effectiveness and success of the method can collaborate to make physics classes more motivated and attractive.

Keywords: Physics Teaching; Lightning; Electricity. 


\section{INTRODUÇÃO}

Os alunos, quando chegam no Ensino Médio, encontram grande dificuldade em relacionar-se com os conteúdos apresentados na disciplina de Física. Por isso, a necessidade em se trabalhar a fim de despertar o interesse, trazer para sala de aula a realidade na qual esse aluno está inserido pode dá-lo a oportunidade de transformar um problema social em algo que seja de uso científico (SOUZA; CARVALHO, 2014, p. 3).

Segundo Ribeiro (2005), a dificuldade no ensino de Física está ligada à necessidade de modificações nos conteúdos dos currículos existentes e nos métodos educacionais, sendo que tais mudanças devem ser baseadas em pesquisas cientificas.

Com base nessas mudanças, buscou-se utilizar novas práticas pedagógicas à luz das metodologias ativas. Essas metodologias, segundo Berbel (2011), baseiamse em formas de desenvolver o processo de aprender, utilizando experiências reais ou simuladas, utilizando a problematização como estratégia de aprendizagem e onde o aluno passa a ter autonomia e participação ativa durante todo o processo. Dentre as metodologias ativas, optou-se pelo método estudo de caso.

O estudo de caso contribui para compreendermos melhor os fenômenos individuais, os processos organizacionais e políticos da sociedade, um fenômeno contemporâneo partindo do seu contexto real, utilizando de múltiplas fontes de evidências. Enfim, um estudo de caso consiste em uma história real ou simulada, com dados reais e com perguntas que estimulem a tomada de decisão.

A sequência didática foi aplicada no $3^{\circ}$ ano do Ensino Médio do IFF campus Cambuci, onde foi utilizado o estudo de caso sobre o tema raios. Para que um raio possa ocorrer, é necessário que existam cargas de sinais opostos entre nuvens ou entre nuvens e o solo; quando isso ocorre, a atração entre as cargas é tão grande que provoca a descarga elétrica. Tais cargas foram nomeadas de cargas positivas e cargas negativas por Benjamin Franklin, por volta de 1750, século XVIII, quando esse realizou grandes descobertas sobre a eletricidade. Além de identificar o sinal das cargas, positivas e negativas, Franklin demonstrou de modo experimental que os raios são um fenômeno de natureza elétrica (SILVA; BARRETO, 2010, p. 89).

Segundo Delizoicov et al (2002), no processo educativo, teoria e prática se associam e a educação é sempre prática intencionalizada pela teoria. Os conteúdos 
passam a ter mais relevância quando os alunos conseguem ver sua funcionalidade por meio de uma prática. Dessa forma, utilizou-se o método estudo de caso para que essa integração da teoria e prática pudesse se tornar possível.

Nesse sentido, o objetivo geral do presente trabalho é investigar quais implicações para a aprendizagem sobre conceitos de eletrostática com a temática raios podem ser obtidas com o uso do método estudo de caso.

\section{Metodologia ativa com enfoque no estudo de caso}

Há muitos anos, estudiosos como Ausubel, Freire, Vygotsky e outros vêm pesquisando como acontecem os processos de ensino e de aprendizagem, buscando uma estrutura cognitiva ao invés da aprendizagem mecânica. E é nesse caminho que sugiram práticas pedagógicas inovadoras, denominadas metodologias ativas.

Berbel (2011, p. 29) salienta que as metodologias ativas contribuem com a promoção da autonomia dos estudantes e que o professor atua como facilitador ou orientador para que o estudante faça pesquisa, reflita e decida por ele mesmo. $\mathrm{Na}$ utilização de metodologias ativas, há uma inversão de papéis, descentralizando-se o foco no professor e centrando o foco no aluno, exigindo sua participação ativa, desafiando-o e motivando-o para construir sua própria aprendizagem. As metodologias ativas baseiam-se em formas de desenvolver o processo de aprender, utilizando experiências reais ou simuladas, buscando condições de solução de acordo com um contexto, ou seja, utilizam problematização como estratégia de aprendizagem.

Diversas formas de metodologias ativas foram elaboradas e categorizadas como aprendizagens colaborativas e aprendizagens cooperativas. Todas as alternativas de metodologias ativas colocam o aluno diante de problemas e/ou desafios que mobilizam o seu potencial intelectual, indo em busca de informações e levando-o para o desenvolvimento da autonomia.

São muitas as possibilidades de metodologias ativas com potencial de levar os alunos a aprendizagens colaborativas para essa autonomia. O estudo de caso é uma delas. Segundo Salete Linhares Queiroz e Luciana Sá, com esse método os alunos são levados à análise de problema e tomada de decisão. O método de estudo de casos é uma variante do método Aprendizado Baseado em Problemas, também conhecido como Problem Based Learning (PBL), criado no final dos anos 60 na Escola 
de Medicina da Universidade de McMaster, Ontário, Canadá onde foi desenvolvido com o objetivo de colocar os alunos em contato com problemas reais, de estimular o pensamento crítico e a habilidade de resolução de problemas, além de desenvolver a aprendizagem da área em questão.

No Brasil, esse método iniciou-se em 1997, inicialmente na Faculdade de Medicina de Marília e a Faculdade de Medicina do Centro de Ciências da Saúde da Universidade de Londrina. Atualmente, o estudo de caso atua em várias áreas. Com muitas variantes do PBL, o estudo de caso é um método que oferece aos estudantes a oportunidade de direcionar sua própria aprendizagem e investigar aspectos científicos e sócio científicos, presentes em situações reais ou simulados. Utiliza-se narrativas que são denominados casos (QUEIROZ; SÁ, 2010, p. 11).

Um estudo de caso é uma história de um fenômeno passado ou atual, elaborado a partir de fontes seguras e é sustentado por um referencial teórico, que orienta as questões e preposições do estudo. É um método específico de pesquisa de campo. Os estudos de campo são investigações dos fenômenos exatamente como eles ocorrem. Para a elaboração de casos, deve-se utilizar as seguintes fontes: artigos de divulgação científica; artigos originais de pesquisa e filmes comerciais, além de recortes de jornal, relatos, cartas, etc. A produção de casos investigativos de boa qualidade deve seguir os aspectos: narrar uma história; despertar o interesse pela questão; ser atual; criar empatia com os personagens centrais; incluir diálogos; relevância para o leitor; utilidade pedagógica; provocar um conflito; forçar uma decisão; ter generalizações e ser curto. O caso pode ser classificado em: casos estruturados, mal-estruturados e de múltiplos problemas. Neste artigo, utiliza-se um caso único estruturado, de forma definida com o problema a ser resolvido (QUEIROZ; SÁ, 2010, p. 17-26).

O objetivo do estudo de caso é chegar a uma compreensão total do fenômeno estudado; no caso desse artigo, compreender sobre os raios e desenvolver um enunciado teórico geral sobre as regularidades deste fenômeno. Nesse aspecto, optou-se por um tipo único de estudo de caso de caráter descritivo, que busca o entendimento do fenômeno raios como um todo, e, através de uma análise qualitativa, explicar ou descrever esse acontecimento natural. Para isso, fez-se necessário o embasamento teórico da questão através da compreensão de assuntos de eletrostática.

\section{A eletrostática e o estudo dos raios}


A eletrostática é a parte da Física que estuda as propriedades e a ação mútua das cargas elétricas em repouso em relação a um sistema inercial de referência. $A$ eletrostática se fundamenta em dois princípios: princípio da atração e repulsão, onde as cargas elétricas de mesmo sinal se repelem e as de sinais opostos se atraem; e o princípio da conservação das cargas elétricas, em que num sistema eletricamente isolado, que não troca cargas elétricas com o meio exterior, a soma algébrica das cargas positivas e negativas é constante (RAMALHO, 1982, p. 2-3).

Os materiais que conservam as cargas nas regiões onde elas surgem são chamados de isolantes. Já aqueles onde as cargas se espalham são denominados condutores. A eletrização entre materiais pode ser por condução, indução e atrito. (RAMALHO, 1982, p.5-9)

Charles Augustin de Coulomb, no final do século XVIII, formulou a equação da força elétrica, conhecida como Lei de Coulomb. A equação formulada é a responsável pelo estudo de atração e repulsão apresentada pelos corpos eletrizados.

Já o campo elétrico desempenha o papel de transmissor de interações elétricas. Campo elétrico é uma grandeza física vetorial usada para definir o módulo da força elétrica exercida a cada unidade de carga elétrica.

O potencial elétrico ou potencial eletrostático de um ponto em relação a um ponto de referência é definido pelo trabalho da força elétrica sobre uma carga eletrizada no deslocamento entre esses dois pontos.

No entanto, quando nos referimos às cargas elétricas em movimento, nos referimos a outra parte da eletricidade, que denominamos eletrodinâmica. Esse movimento de cargas gera corrente elétrica. A corrente elétrica é o fluxo ordenado de partículas com cargas elétricas. Para que se forme a corrente elétrica, é necessária uma fonte que forneça energia para as cargas elétricas se movimentarem. É o que chamamos de diferença de potencial (ddp) ou tensão, ou voltagem entre dois pontos do circuito (RAMALHO, 1982, p. 9-100).

Com todo esse assunto abordado, entende-se que os raios são descargas elétricas naturais que, para serem produzidas, necessitam que haja entre dois pontos da atmosfera uma tensão média da ordem de 25.000 .000 volts. Nessas condições, a intensidade de corrente é avaliada em torno de 200.000 A. Os raios se formam quando certa região de uma nuvem acumula excesso de carga elétrica, positiva ou negativa. Se isso ocorre, o raio é o meio de desfazer a tensão, por meio da transmissão da 
eletricidade. O movimento intenso de massas de ar no interior das nuvens gera atrito entre moléculas de água e gelo, causando a eletrização da nuvem.

\section{METODOLOGIA}

A pesquisa teve cunho investigativo de natureza qualitativa, utilizando o estudo de caso interpretativo (MOREIRA, 2016, p. 15), onde se colheram dados descritivos para desenvolver uma possibilidade de interpretação à luz da questão foco.

"O interesse central desta pesquisa está em uma análise dos significados explicitados por uma observação participativa, isto é, o pesquisador fica imerso no fenômeno de interesse" (MOREIRA; ROSA, 2016, p. 7), coletando os significados atribuídos pelos alunos e suas ações em uma realidade socialmente construída.

Como já mencionado, aplicou-se o caso em uma turma de 3.ano do Ensino Médio do curso Agroecologia de uma escola pública. A turma, composta de 24 alunos, foi dividida em cinco grupos, quatro grupos com 5 alunos e 1 grupo com 4 alunos.

No primeiro momento, dividiu-se a turma em grupos, onde se apresentou 0 caso intitulado "Enchentes nas tempestades com raios nas grandes cidades" (Figura 1) sobre o fenômeno natural raios.

Escola: IFF - Campus Cambuci.

Cambuci/ RJ, 05/04/2019. 
Figura 1 - Caso elaborado para a sequência didática implementada.

\section{PRIMEIRO MOMENTO: Estudo de caso}

Enchentes e tempestades com raios nas grandes cidades

Há aproximadamente 1 ano atrás, Belo Horizonte sofreu com as enchentes. Poucos minutos de chuva forte e carros foram arrastados pela correnteza, avenidas alagadas, quedas de árvores e houve morte de três pessoas, uma adolescente de 16 anos foi arrastada para o bueiro e não resistiu.

Eu Alan (16 anos), sempre morei em BH e fiquei assustado com o ocorrido. Os estrondos dos raios pareciam estremecer o prédio onde moro. No momento do temporal eu estava em casa com minha mãe Alice, esperando a chegada do meu pai, que devido aos alagamentos, ficou ilhado no trabalho.

Sem energia, não pude fazer contato com ele e me disseram que na hora da tempestade não é bom usar o telefone, principalmente se estiver carregando. Por horas ficamos aguardando ansiosos pela chegada de meu pai. Por volta de 21:30 ele abre a porta, ficamos felizes e aliviados por nada de ruim ter acontecido. Ao mesmo tempo, fiquei intrigado em relação ao uso do celular. Será que o aparelho telefônico atrai corrente elétrica e provoca uma descarga na pessoa que usa? Quais medidas eu poderia tomar para que não seja atingido por uma descarga elétrica?

Será distribuído o caso para a turma analisar em grupo (3 ou 4 alunos) o problema em questão.

Em seguida, o professor deverá recolher as respostas para ser analisado. E prosseguiremos para o segundo momento.

\section{Fonte: elaboração própria.}

Após a leitura do caso, os alunos foram instigados a solucionar dois problemas relacionados ao assunto, com o objetivo de investigar os conceitos empíricos, de senso comum e científicos presentes no grupo.

No segundo momento, apresentaram-se os novos conhecimentos sobre o conteúdo eletrostática com ênfase no fenômeno natural, raios, em seguida foram listados alguns exercícios sobre o assunto trabalhado nos slides anteriormente. Houve também a exibição de vídeo intitulado "De onde vem o raio?”, para se trabalhar alguns conceitos sobre eletrização, corrente elétrica e diferença de potencial na formação dos 
raios. Nesse passo também foi utilizado um jogo com questões via aplicativo Plickers como ferramenta avaliativa.

E, no terceiro momento, foi retomado o caso, para solução final às questões iniciais. As respostas iniciais e finais dadas pelos alunos foram analisadas comparativamente para fins de evolução do conhecimento.

\section{RESULTADOS}

O caso "Enchentes e tempestades com raios nas grandes cidades" foi aplicado com o objetivo de promover nos discentes competências e habilidades, como interpretação de textos, resolução de problemas e tomada de decisões, além de proporcionar a aplicação dos conceitos físicos em situações reais.

Desde o início da aplicação desta sequência, dividiu-se a turma em 5 grupos (G1, G2, G3, G4 e G5), que deveriam ler e interpretar o caso e responder por escrito as possíveis soluções para as situações-problema propostas no caso, antes de apresentar os conteúdos de eletrostática que envolvem o assunto raios, que denominou-se passo inicial.

Após a aplicação da sequência didática pelo método estudo de casos, que é uma estratégia didática na qual os elementos principais do estudo de casos são apresentados aos discentes com propósitos ilustrativos, sem necessidade de oferecer uma visão completa dos fatos, as respostas dos grupos foram analisadas qualitativamente. Segundo Moreira e Rosa (2013, p. 7-14), a pesquisa qualitativa é chamada também naturalista porque não envolve manipulação de variáveis, nem tratamento experimental (é o estudo do fenômeno em seu acontecer natural).

No caso em questão, foram elaboradas duas perguntas de cunho investigativo, com o objetivo de sondar os conhecimentos prévios dos alunos, o que se chamou de conhecimento empírico. Na questão 1, observou-se a categoria de senso comum, de conhecimento empírico e conhecimento científico.

Com relação à questão 2, observou-se apenas os conhecimentos empírico e científico. Em relação à primeira fase da resolução do caso, os estudantes identificaram o problema proposto pela situação, conforme os trechos apresentados no Quadro 1. De acordo com Sá e Queiroz (2009), para resolver um caso, os estudantes devem passar por três etapas: identificação e definição do problema; 
acessar, avaliar e usar informações necessárias à sua solução; e, por fim, apresentar a solução do problema. Assim, podemos constatar que os cinco grupos atingiram esses três estágios, pois todos apresentaram soluções para o caso.

A primeira questão, "Qual será o motivo para não poder usar o celular no momento de tempestade?", teve por objetivo instigar os discentes para pensar nos perigos provocados pelos aparelhos telefônicos ligados às tomadas. Devido ao crescente número de acidentes com celulares, fez-se necessário abordar esse assunto com os adolescentes, para que possam ter conhecimentos básicos de eletrostática e conheçam os perigos que há em sua própria moradia.

Considerou-se como foco central dessa questão investigar os conhecimentos prévios dos alunos com relação a um assunto atual e relacioná-los ao que ocorre em caso de tempestades. O estudo de caso interpretativo nos remete ao tema da teoria fundamentada. Este tipo de estudo de casos foi aplicado na análise dos dados por ter caráter investigativo e fundamentar a teoria, isto é, induz uma teoria a partir de dados descritivos muito ricos. Porém, não se trata de uma teoria formal no sentido usado nas ciências naturais, também não do "método de indutivista". Pretende-se fazer uma análise teórica, com base nas hipóteses, e que seja de caráter compreensivo.

Escola: IFF - Campus Cambuci.

Cambuci/ RJ, 23/06/2019.

Quadro 1 - Categorização da primeira questão.

\begin{tabular}{|l|l|l|}
\hline Categoria & \multicolumn{1}{|c|}{ US passo Inicial } & US Passo Final \\
\hline & $\begin{array}{l}\text { Não é recomendado o uso do } \\
\text { celular durante as tempestades. } \\
\text { (G1) } \\
\text { Acidentes com pessoas que } \\
\text { atendem o telefone no carregador e } \\
\text { Conhecimento } \\
\text { Comum }\end{array}$ & $\begin{array}{l}\text { Evitar mexer no celular enquanto } \\
\text { estiver carregando. (G1) } \\
\text { Não andar descalço. (G1) } \\
\text { Aparelhos eletrônicos absorvem } \\
\text { energia e se acontecer uma } \\
\text { descarga elétrica na rede de luz } \\
\text { pode sobrecarregar. (G2) } \\
\text { Não ficar sem blusa, não olhar para } \\
\text { o espelho, desligar todos as } \\
\text { tomadas de casa. (G3) } \\
\text { A eletricidade do celular e suas } \\
\text { partes metálicas atraem os raios. } \\
\text { (G3) } \\
\text { O raio pode acertar a casa. (G3) }\end{array}$ \\
\hline
\end{tabular}




\begin{tabular}{|c|c|c|}
\hline & $\begin{array}{l}\text { Não ficar com coisas metálicas na } \\
\text { mão. (G4) } \\
\text { Poder até pode, mas corre o risco } \\
\text { de ser atingido pelo raio. (G5) }\end{array}$ & \\
\hline $\begin{array}{l}\text { Conhecimento } \\
\text { Empírico }\end{array}$ & $\begin{array}{l}\text { O celular é um condutor de energia. } \\
\text { (G1) } \\
\text { O material que forma o aparelho } \\
\text { também contém metal. (G1) } \\
\text { O raio pode fazer aparelhos } \\
\text { queimarem. Não ficar com coisas } \\
\text { metálicas na mão. (G4) }\end{array}$ & $\begin{array}{l}\text { O celular é um condutor de } \\
\text { eletricidade. (G1) } \\
\text { Um raio pode atingir o para-raios } \\
\text { e chegar nas partes metálicas } \\
\text { da casa. (G4) }\end{array}$ \\
\hline $\begin{array}{c}\text { Conhecimento } \\
\text { Científico }\end{array}$ & $\begin{array}{l}\text { Utilização de ondas } \\
\text { eletromagnéticas. (G1) } \\
\text { O metal é condutor de energia. } \\
\text { (G1) } \\
\text { A descarga elétrica pode atingir os } \\
\text { fios condutores de energia da casa } \\
\text { chegando ao usuário do celular } \\
\text { (G3) } \\
\text { Um raio pode acertar a rede elétrica } \\
\text { e fazer os raios queimarem. (G4) }\end{array}$ & $\begin{array}{l}\text { Não se pode utilizar o celular } \\
\text { num momento da tempestade. } \\
\text { Se torna mais perigoso ainda se } \\
\text { estiver conectado ao carregador } \\
\text { pois o mesmo estará ligado a } \\
\text { uma rede elétrica. (G1) } \\
\text { Não se deve usar o celular } \\
\text { carregando em dias de } \\
\text { tempestades, pois um raio pode } \\
\text { atingir o para-raios. (G4) } \\
\text { Os raios são descargas elétricas } \\
\text { formadas a partir da junção das } \\
\text { cargas positivas do solo. (G4) } \\
\text { Não é recomendado utilizar o } \\
\text { celular carregando durante uma } \\
\text { tempestade, pois se cair um raio } \\
\text { na sua residência, toda sua } \\
\text { estrutura ficará eletrizada. (G5) }\end{array}$ \\
\hline
\end{tabular}

Fonte: elaboração própria.

Assim, partiu-se da análise dos conhecimentos prévios e qual foi a aquisição de conceitos que tenham contribuindo para a aprendizagem em eletrostática. No quadro 1 acima, apresentam-se os registros do conhecimento de senso comum, prévio, que se chamou de empírico, e conhecimento científico.

Como pode-se observar no Quadro 1, 100\% da turma não apresentou um conhecimento relacionado ao seu senso comum no passo final. Esses textos confirmam a ideia de Cachapuz e colaboradores (2011), de que as hipóteses são os guias de uma pesquisa.

Com relação ao conhecimento empírico, nota-se que a maioria dos grupos, com exceção do grupo 5, apresentou o que Ausubel chama-se de subsunçores e que os grupos estavam prontos para adquirir novos conhecimentos. Ficou implícito pelas respostas dos grupos que se deve evitar usar o aparelho telefônico quando o mesmo 
estiver na tomada, que no fio há corrente elétrica de potencial equivalente ao da tomada e que ao estar carregando, por mais que a bateria seja adequada, deve-se tomar todo o cuidado. Observou-se também que o avanço tecnológico tem estimulado as pessoas a adquirirem carregadores sem que tenham procedência. No caso em questão, relacionou-se o uso do celular no momento de tempestade, por isso, todo o cuidado é pouco, ainda mais em regiões brasileiras com maior incidência desse fenômeno.

Percebeu-se que nessa questão os alunos apresentavam um senso comum geral, mas, após explicações do professor, esse conhecimento foi modificado, apresentando indícios de aprendizagem significativa, pois acrescentou conhecimentos empíricos e científicos à questão proposta.

Na segunda questão, "Quais medidas eu poderia tomar para que não seja atingido por uma descarga elétrica?", buscou-se conhecer os conhecimentos que os alunos tinham a respeito de uma descarga elétrica; como ocorre uma descarga elétrica; quais cuidados deve-se ter em dias de tempestades e quais assuntos físicos estão correlatados.

De acordo com Moreira (2016, p. 6), o interesse central dessa pesquisa está em uma interpretação dos significados atribuídos pelos sujeitos em suas ações em uma realidade socialmente construída, através de observação participativa, isto é, o pesquisador fica imerso no fenômeno de interesse. Dessa forma, nesta questão abordaram-se as categorias que envolvem o conhecimento empírico e o conhecimento científico dos alunos, e observou-se que antes dos conteúdos serem apresentados, havia algum conhecimento observável e, após o desenvolvimento de toda sequência didática proposta, houve acréscimos de conhecimentos adquiridos, o que levou ao indício de uma aprendizagem significativa dos conceitos sobre o assunto eletroestática, conforme recortado e descrito no quadro a seguir, referente à 2 questão do estudo de caso.

Escola: IFF - Campus Cambuci.

Cambuci/ RJ, 23/06/2019.

Quadro 2: Categorização da segunda questão 


\begin{tabular}{|c|c|c|}
\hline \multicolumn{3}{|c|}{ 2- Quais medidas poderia tomar para não ser atingido por uma descarga elétrica? } \\
\hline Categoria & US passo Inicial & US Passo Final \\
\hline $\begin{array}{c}\text { Conhecimento } \\
\text { Empírico }\end{array}$ & $\begin{array}{l}\text { Não ficar com pés molhados, } \\
\text { ir para dentro de um carro, } \\
\text { pois é protegido pelos pneus } \\
\text { e a carcaça é metálica. (G3) } \\
\text { O raio pode fazer aparelhos } \\
\text { queimarem. Não ficar com } \\
\text { coisas metálicas na mão. } \\
\text { (G4) } \\
\text { Evitar ficar exposto em local } \\
\text { elevado. (G5) }\end{array}$ & $\begin{array}{l}\text { Um raio pode atingir o para-raios e } \\
\text { chegar nas partes metálicas da casa. } \\
\text { (G4) ficar isolado em áreas } \\
\text { Não ficar (G5) } \\
\text { descampadas. }\end{array}$ \\
\hline $\begin{array}{c}\text { Conhecimento } \\
\text { Científico }\end{array}$ & $\begin{array}{l}\text { Não sair de casa no momento } \\
\text { da tempestade, não ficar } \\
\text { próximo à árvores, } \\
\text { postes,etc. (G1) } \\
\text { Evitar lugares abertos, evitar } \\
\text { água. (G2) } \\
\text { Uma forma de se proteger } \\
\text { contra raios é ficar dentro de } \\
\text { casa, não ficar com coisas } \\
\text { metálicas na mão, nem fios } \\
\text { de eletricidade, lugares altos } \\
\text { e em contato com a água. } \\
\text { (G4) } \\
\text { Evitar contato com materiais } \\
\text { de alta condutividade elétrica } \\
\text { (ferro, carbono). (G5) }\end{array}$ & $\begin{array}{l}\text { Não se pode utilizar o celular num } \\
\text { momento da tempestade. Se torna } \\
\text { mais perigoso ainda se estiver } \\
\text { conectado ao carregador pois o } \\
\text { mesmo estará ligado a uma rede } \\
\text { elétrica. (G1) } \\
\text { Não ficar perto de objetos que } \\
\text { conduzem eletricidade. (G1) } \\
\text { Se possível evitar sair de casa. Caso } \\
\text { esteja fora de casa, não ficar embaixo } \\
\text { de árvores, evitar contato com } \\
\text { materiais que conduzem eletricidade. } \\
\text { (G2) } \\
\text { Não é recomendado utilizar o celular } \\
\text { carregando durante uma tempestade, } \\
\text { pois se cair um raio na sua residência, } \\
\text { toda sua estrutura ficará eletrizada. } \\
\text { (G5) }\end{array}$ \\
\hline
\end{tabular}

Fonte: elaboração própria.

Notou-se que houve mudança de comportamento em relação ao senso comum e aos subsunçores, conhecimentos empíricos existentes; ainda, se verificou que os alunos são observadores e que essa característica permaneceu antes e depois da explicação dada pelo professor sobre os conteúdos abordados de eletrostática. Em relação aos conhecimentos científicos, constatou-se que todos os grupos acrescentaram informações científicas, dando indícios de ter ocorrido aprendizagem significativa dos conteúdos abordados, pois demonstra acréscimo de competências e habilidades das apresentadas anteriormente.

Encontrar metodologias de ensino que ajudem os discentes a realizarem atividades que levam em consideração suas experiências, interesses e estimulem a tomada de consciência e participação nas decisões de caráter sócio-científico são de vital importância para um bom encaminhamento da educação básica no país (SILVA et al., 2011). Desta forma, constatamos que o estudo de caso motivou os discentes e desenvolveu habilidades como interpretação de problemas e investigação de 
soluções, auxiliando-os na capacidade de tomada de decisões e mostrou indícios de aprendizagem de novos conceitos relacionado ao conteúdo de física abordado no caso, eletroestática.

\section{CONSIDERAÇÕES FINAIS}

Os nossos principais objetivos com a aplicação do caso "Enchentes e tempestades com raios nas grandes cidades" foi: investigar quais implicações para a aprendizagem sobre conceitos de eletrostática com a temática raios podem ser obtidas com uso do método estudo de caso. Através dos resultados obtidos, percebemos que atingimos esses propósitos. O estudo de caso é um método que exige leitura e interpretação para que se possa compreender o problema proposto. Apesar de o caso aplicado apresentar a tarefa de forma clara, a mesma precisou ser entendida pelos discentes para que pudesse sistematizar os próximos passos da sequência didática proposta. Esta metodologia de ensino propiciou um ambiente de interação entre os discentes na busca de respostas que solucionassem o problema de como se comportar em dias de tempestades.

Eles propuseram hipóteses, pesquisaram no livro didático adotado pela escola, debateram sobre as possíveis posturas em dias de tempestades, para enfim formularem suas respostas e soluções para o caso. Desta forma, fica evidente que a metodologia de ensino utilizada desenvolveu habilidades como interpretação de problemas (interpretação do caso), pesquisa (resolução de lista de exercícios sobre o tema) investigação de possíveis soluções (análise e julgamento das informações obtidas) bem como a capacidade de tomada de decisões para a proposição de respostas e soluções para o caso.

Além disso, esta atividade proporcionou a aplicação dos conhecimentos de Física em situações reais, as quais faziam parte da rotina dos próprios discentes. Outra vantagem da história narrada no caso aplicado foi a identificação da turma com os problemas vivenciados em dias de tempestades. Acredita-se que a criação de um caso sobre tempestades, assunto presente no cotidiano dos discentes, deu significado ao conteúdo de eletroestática e conceitos abordados em aula, contribuindo para um 
ensino voltado para o desenvolvimento pessoal, com a aplicação dos conteúdos de Física em situações cotidianas.

O método estudo de casos promoveu o trabalho em grupo, a capacidade de tomada de decisão e a interpretação de problemas reais, desta forma concretizando os objetivos que tínhamos traçado quando escolhemos esta temática e metodologia de ensino.

Com a aplicação da sequência didática embasada no método de estudo de caso, foi possível verificar que contribuiu para a aprendizagem de conceitos científicos colaborando desta forma, para uma aprendizagem significativa dos conceitos de eletroestática de uma forma mais dinâmica em sala de aula. Acredita-se que a eficácia e sucesso do método possam colaborar para tornar as aulas de Física mais motivadas e atraentes. Além disso, com este artigo esperamos contribuir com mais uma proposta de utilização do estudo de casos no nível médio, tanto para a área de ensino de Física, bem como para professores que estejam em busca de estratégias de ensino diferenciadas.

\section{Referências}

BERBEL, Neusi Aparecida Navas. As metodologias ativas e a promoção da autonomia de estudantes. Semina: Ciências Sociais e Humanas, Londrina, v.32, n.1, p. 25-40, jan./jun. 2011

BOCAFOLI, F. Exercícios de vestibulares com resolução comentada sobre condutor em equilíbrio eletrostático - blindagem eletrostática, 2019. Disponível em: < http://fisicaevestibular.com.br/novo/eletricidade/eletrostatica/16642/exercicios-de-vestibulares-com-resolucao-comentada-sobre-condutor-emequilibrio-eletrostatico-blindagem-eletrostatica>.

BOCK, A. M. B.; FURTADO, O.; TEIXEIRA, M. de L. T. Psicologias: uma introdução ao estudo de psicologia. São Paulo: Editora Saraiva, 1999.

Brasil Escola. Exercícios sobre Corrente Elétrica(adaptação). 2019, questão 4. Disponível em: <https://exercicios.brasilescola.uol.com.br/exerciciosfisica/exercicios-sobre-corrente-eletrica.htm\#resp-4>.

CATUNDA, C; KIKO MISTRORIGO, K. Onde Vem o Raio e o Trovao? TV PinGuim. Episódio 20, 2015. Disponível em: <https://youtu.be/EjINfH5z08w>. 
COELHO; Rafael Otto. O Uso da Informática no Ensino de Física de Nível Médio. Pelotas/RS 2002. Disponível em:< http://www2.pelotas.ifsul.edu.br/coelho/inf_ ens_fis_med.pdf>.

GOUVEIA, R. Toda Matéria. Blindagem Eletroestática. 2011-2019. Disponível:< https://www.todamateria.com.br/eletrostatica/>.

HELERBROCK, R. Mundo Educação. Exercício sobre Campo Elétrico. 2015. Disponível: < https://exercicios.mundoeducacao.bol.uol.com.br/exerciciosfisica/exercicios-sobre-campo-eletrico.htm>.

MOREIRA, M. A. A Teoria de Aprendizagem de David Ausebel como Sistema de Referência para a Organização de Conteúdo de Física. Revista Brasileira de Física. Vol. 9, N. 1, 1979, p. 276. Disponível em: < http://sbfisica.org.br/bjp/download/v09/v09a19.pdf >.

; ROSA, P. R. S. Pesquisa em ensino: métodos qualitativos e quantitativos (apostila de compilação de trabalhos publicados) 2. ${ }^{\text {a }}$ Edição. Porto Alegre: UFRGS, 2016, p.4-16. Disponível em:<http://moreira.if.ufrgs.br/Subsidios11.pdf $>$.

OSTERMANN; C.; F.; C.J. H. Teoria de Aprendizagem. Textos Introdutório. Questões de Eletrostática" em Só Física. Virtuous Tecnologia da Informação, 2008-2019. Disponível em:

<http://www.sofisica.com.br/conteudos/exercicios/eletrostatica.php>.

RAMALHO, J. F. Os fundamentos da Física 3 - Eletricidade, São Paulo: Ed. Moderna, 1982, p. 2-100.

RIBEIRO, M. R. Análise das dificuldades relacionadas ao ensino de Física no nível médio. 2005. 47f. Monografia-Universidade Federal de Uberlândia, Santa Monica, 2005.

SÁ, L. P. Instituto de Química de São Carlos, Universidade de São Paulo. São Carlos - SP, Brasil. 2007, p. 732.

; QUEIROZ, S. L. Estudo de Casos no Ensino de Química. Campinas: Editora Átomo, 2009, p. 95.

. Estudo de Casos na promoção da argumentação sobre questões sócio científicas no ensino superior de Química. Tese (Doutorado em Química) Universidade Federal de São Carlos, São Carlos, 2010, p. 278.

. A argumentação no ensino superior de Química: investigando uma atividade fundamentada em estudos de Casos. Dissertação. (Mestrado em Ciências) - Universidade de São Paulo, São Carlos, 2006, p. 152.

; FRANCISCO, C. A; QUEIROZ, S. L. Universidade Federal do Rio Grande do Sul - Instituto de Física. 2010, p. 11-12. 
; QUEIROZ, Salete Linhares. Estudo de Caso no Ensino de Química. Ed. Átomo.2 ${ }^{\mathrm{a}}$ ed. Campinas, 2010, p.1-17.

TORRES et al. Física Ciências e Tecnologia. Eletromagnetismo. Física Moderna. Editora Moderna. Volume 3, p. 308.

PAZINATO, S. M. ; BRAIBANTE, F. M. E. O estudo de Caso como estratégia metodológica para o ensino de química no nível médio. Universidade Federal de Santa Maria, Programa de Pós-Graduação em Educação em Ciências: Química da Vida e Saúde. Campus UFSM. Santa Maria - RS. 2014, p. 11.

QUEIROZ, S. L.; SÁ, L. P.; FRANSCISCO, C. A. Estudos de Caso em Química.

Química Nova, São Paulo, v. 30, n. 3, 2007, p. 731-739. 